\title{
Comparative Analysis of Permanent Magnet Synchronous Generators with Mechanical Energy Storage according to Machine Types
}

\author{
Yu-Seop PARK \\ Dept. of Electrical Engineering, Korea National University of Transportation, Chungju, Korea \\ yspark@ut.ac.kr
}

\begin{abstract}
This paper deals with the comparative investigation on the performance of various permanent magnet wind power generators according to magnetization patterns and stator coil winding types for wind power applications. With slotless stator core structure, vertical and Halbach magnetization patterns are applied to the three types of coil pitch windings. Based on finite element method, the electromagnetic field analysis is performed, and one of the analysis models is manufactured for its experimental verification. In this study, the machines have almost identical values of induced voltage and resistance which are considered as important equivalent circuit parameters, so their reasonable comparison can be made. Besides, since the generators are integrated with a mechanical energy storage system, the influence of the energy storage on the generator performance is addressed based on the measured phase current including harmonics. From the analysis results presented in this study, the better choice by considering machine topology is proposed.
\end{abstract}

Index Terms - converter, energy storage, induction machine, power losses, wind power generator.

\section{INTRODUCTION}

Due to high interests on renewable energy systems, active researches on wind power generators have been very widely performed. As presented in plenty of previous studies, the category of the wind power generators can be various [1], and the permanent magnet synchronous generator (PMSG) with direct mechanical connection to the wind turbine has become popular with superior performance in terms of energy density and efficiency. In previous literatures, this type of machine was studied for various topics, for instance, machine design [2-3], performance evaluation [4-5], loss calculation [6], sensorless control [7], fault characteristics [8-9], dynamic analysis [10], and power electronics with control [11-14]. Mostly focusing on the machine topology, such as PM flux direction, stator structure, rotor position and coil windings, the generators can be divided into several types, and it is also aware that the magnetization patterns of the PMs are very important design factor to determine the machine characteristics. In general, compared to the conventional radial or parallel magnetization patterns, it is known that the Halbach magnetization pattern can have the benefits from its sinusoidal magnetic field [15].

On the other hand, the storage of the generated energy is also a hot issue in related industry. The energy storage system can be also various, such as a chemical battery and super capacitor. Besides, the mechanical energy storage

This was supported by Korea National University of Transportation in 2021. system (MESS) is also one of the attractive candidates to be integrated with the wind power generation systems, so the studies on MESS were also widely performed. The MESS is operated as a motor when the generated energy is sufficient while it is also operated as a generator to reuse the stored energy. The type of electrical machines for MESS can be also various, and the previous studies applied an induction machine [16], a switched reluctance machine [17], and a permanent magnet synchronous machine (PMSM) [18] for their flywheel energy storage system. Although the PMSM shows higher energy density and superior performance, some applications still prefer the other types of machines due to the high price and the demagnetization of the rareearth materials for PMs.

In this paper, a PMSG for wind power generator is integrated with power converter and MESS as shown in Fig. 1. Among various machine types, with the reason of its wide use in industry, this paper employed a squirrel induction machine (IM) for the MESS, and the influence of power converter on the PMSG for wind power application is investigated while the mechanical energy is being stored in motoring mode. The PMSGs addressed in this study is largely distinguished by the stator coil pitch (CP) and the magnetization patterns of the PMs. Based on finite element method (FEM), the electromagnetic field analysis of various PMSGs is performed, and one of the analysis models is manufactured for experimental verification in Chapter II. Besides, in Chapter III, the induction machine for the MESS is integrated with the PMSG and power converter, and the systemic characteristics are measured while the mechanical energy is being stored. Furthermore, for the reasonable comparison, the PMSGs have almost identical equivalent circuit parameters, such as induced voltage and resistance, and the measured phase current from the experiment is employed to comparatively investigate the influence of the MESS on PM wind power generators in Chapter IV. Finally, the analyzed results are discussed, while the conclusion of this study is presented in Chapter V.

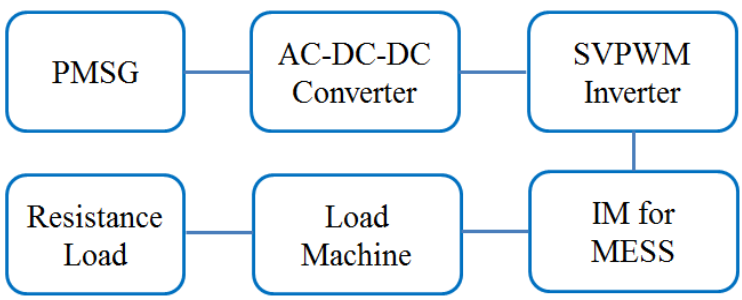

Figure 1. Integrated system concept of PMSG, power converter and MESS for wind power generator application 


\section{COMPARATIVE INVESTIGATION ON ANALYSIS MODELS BY CONSIDERING MACHINE TOPOLOGY}

In the design of electrical machines, the cogging torque reduction is very important since it causes the noise and vibration while the machine is being operated. Therefore, various cogging torque reduction methods can be employed, such as the skew and slotless core structure. Although those methods reduce the energy density of the machines, the cogging torque can be dramatically reduced with the techniques. In particular, since the PM wind power generators should start rotating in spite of low wind speed condition, the cogging torque must be eliminated. As a result, for comparative investigation of generators, this study employed slotless stator core type whose cogging torque is not existed. However, the slotless stator has relatively larger magnetic air-gap in comparison with the slotted stator, so its energy density is low requiring more machine volume. In this view point, the Halbach magnetization patterns can be employed to improve the machine performance. While it can have higher energy density, the rotor core can be eliminated or can be substituted to non-magnetic material. In [19], the authors employed the pattern in their linear generator, but their system was not integrated with MESS.

As mentioned above, the generators in this study are largely divided into two categories according to PM magnetization patterns and coil winding types as shown in Fig. 2. In other words, for PM magnetization patterns, conventional parallel type and Halbach type are employed, while three stators with different CPs (9.0, 6.0 and 7.5) are respectively employed to the rotors with the magnetization patterns. In the figure, in Fig. 2 a) - c), the parallel type is integrated with three different stators, and the Halbach type is also presented with the stators in Fig. 2 d) - f). In addition, as presented in Table I, the machines have identical number of poles and outer/inner diameter values while different stack length and coil turns are applied to have almost identical equivalent circuit parameters, such as the no-load induced voltage and the resistance for reasonable comparison.

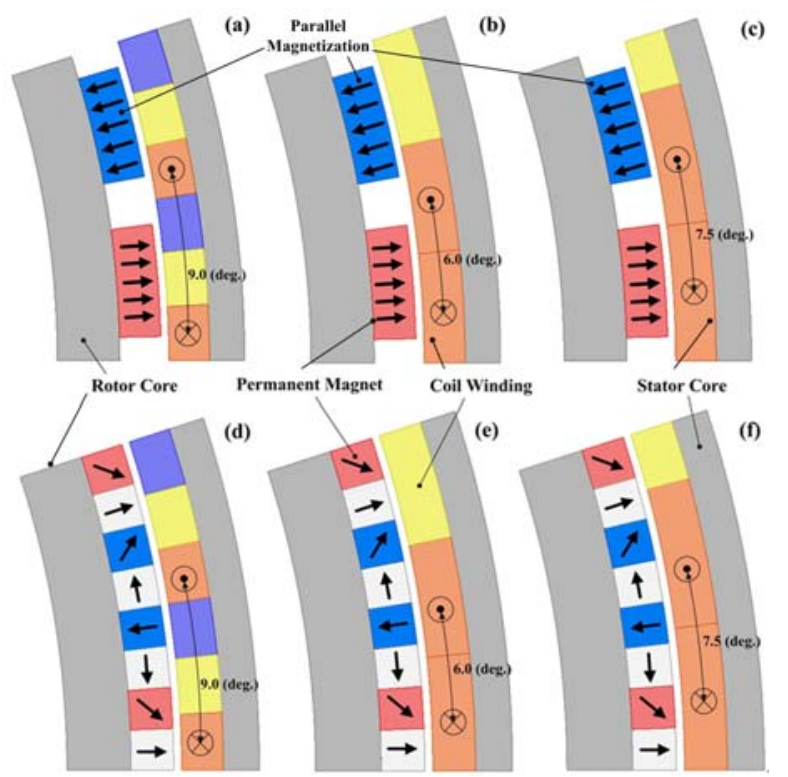

Figure 2. Comparative analysis models according to PM magnetization patterns and stator coil winding topology (1/20 model): (a) Model A, (b) Model B, (c) Model C, (d) Model D, (e) Model E, (f) Model F.
TABLE I. DESIGN SPECIFICATION OF ANALYSIS MODELS

\begin{tabular}{c|c|c|c|c|c|c}
\hline \hline & A & B & C & D & E & F \\
\hline \hline Magnetization Pattern & \multicolumn{3}{|c|}{ Parallel } & \multicolumn{3}{c}{ Halbach } \\
\hline Coil Pitch (deg.) & 9 & 6 & 7.5 & 9 & 6 & 7.5 \\
\hline Number of Poles & 40 & 40 & 40 & 40 & 40 & 40 \\
\hline Outer Dia. of Stator (mm) & 286 & 286 & 286 & 286 & 286 & 286 \\
\hline Inner Dia. of Stator (mm) & 277 & 277 & 277 & 277 & 277 & 277 \\
\hline Outer Dia. of Rotor (mm) & 254 & 254 & 254 & 254 & 254 & 254 \\
\hline Inner Dia. of Rotor (mm) & 238 & 238 & 238 & 238 & 238 & 238 \\
\hline Stack Length (mm) & 85 & 133 & 166 & 59 & 75 & 94 \\
\hline Remanence of PMS (T) & 1.27 & 1.27 & 1.27 & 1.27 & 1.27 & 1.27 \\
\hline Turns per Phase (turns) & 760 & 650 & 520 & 920 & 960 & 768 \\
\hline Resistance (ohm) & 12.0 & 12.0 & 12.0 & 12.1 & 12.0 & 12.0 \\
\hline Inductance (mH) & 4.1 & 6.5 & 7.7 & 4.2 & 8.0 & 9.5 \\
\hline Voltage (Vrms,150rpm) & 94.2 & 94.8 & 94.3 & 94.4 & 94.0 & 94.0 \\
\hline \hline
\end{tabular}

On the other hand, when it comes to inductance, their values have a bit large difference, but it is not crucial since the machines are operated in very low rotational speed condition. It will be demonstrated by showing almost identical output power curve which can be derived by equivalent circuit method and experimental verification.

The flux density of the PMSGs is directly related to the induced voltage, and the magnetization patterns and the stator coil topology can have high influence on the machine performance.

For the electromagnetic field analysis, the magnetic vector potential is defined by (1). Here, $n$ is the coefficient of space harmonics and $p$ is the number of pole pairs.

$$
\mathrm{A}=A_{z n}(r) e^{j(n p \theta)} \mathrm{i}_{z}
$$

The Maxwell's equation can be expressed by (2). Here, $M$ is magnetization shown in (3). Based on those equations and boundary conditions, the flux density in radial component and induced voltage can be obtained by (4) and (5). Here, $N$ and $L$ are respectively, number of turns and stack length [20].

$$
\begin{aligned}
& \nabla^{2} \mathrm{~A}=-\mu_{0}(\nabla \times \mathrm{M}) \\
& \mathrm{M}=\sum_{n=-\infty, \text { odd }}^{\infty}\left[M_{r} e^{j n \theta} \mathrm{i}_{r}+M_{\theta} e^{j n p \dot{\mathrm{i}}_{\theta}}\right] \\
& B_{r}=\frac{j n p}{r} A_{z} \\
& e=-\frac{d \lambda}{d t}=-j n p \omega N L A_{t}
\end{aligned}
$$

For the comparison, the flux density by only PMs is analyzed in air-gap. In general, the flux density is considered as very important factor for the design of electrical machines due to its close relevance to various performance characteristics. In this analysis, the current in stator coil winding is zero so that the armature reaction is not existed. Fig. 3 shows radial component of flux density according to the PM magnetization patterns. The conventional pattern means the parallel magnetization, and the visible difference can be found. In particular, as shown in Fig. 4, the harmonics are eliminated in Halbach type. Since the radial component is dominant to determine the waveform of the induced voltage, Halbach pattern has low total harmonic distortion (THD) in general. 

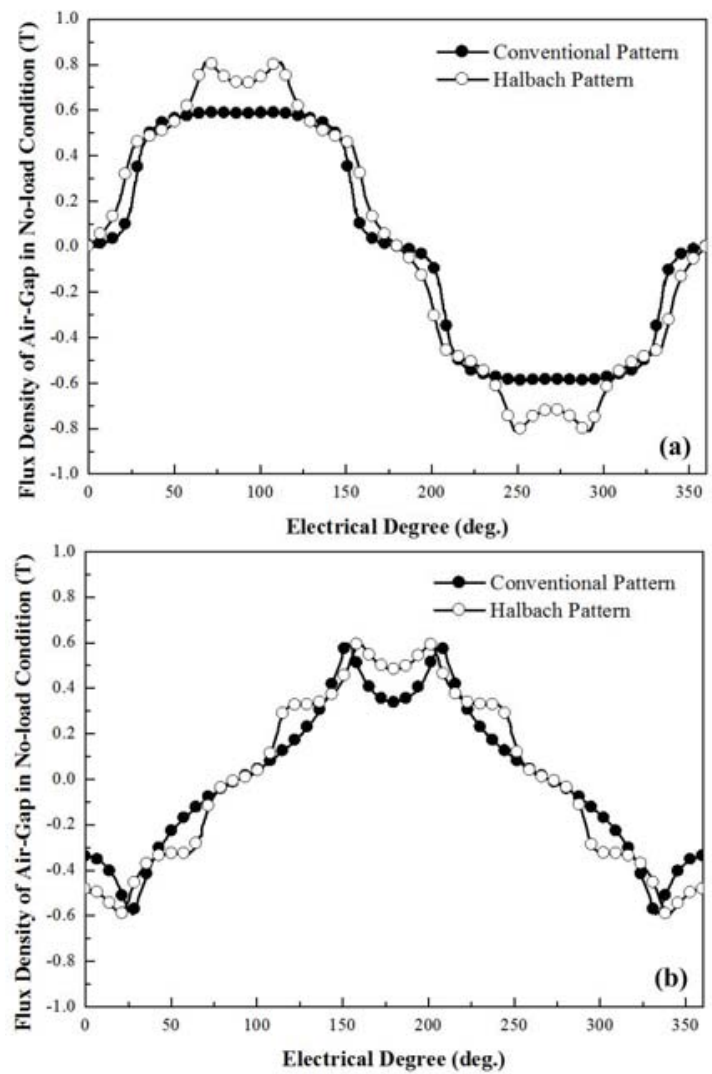

Figure 3. Flux density of air-gap in no-load condition according to PM magnetization patterns: (a) radial component, (b) tangential component

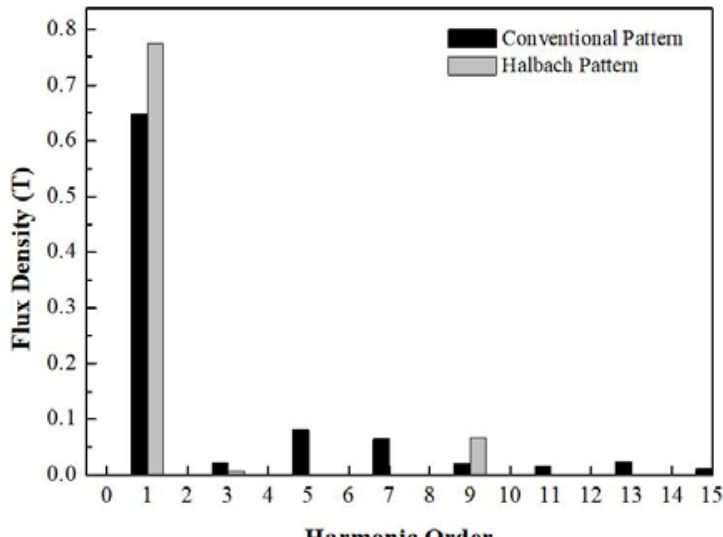

Figure 4. FFT results of radial component of flux density in no-load condition

On the other hand, the armature reaction field can also have high influence on machine performance as well, so the flux density by the stator current is additionally analyzed according to stator coil types. For this analysis, the current conditions presented in Table II are employed. As can be confirmed in the table, the analysis considers the influence of each phase current, and it can be confirmed that the condition $\mathrm{D}$ where all the three phase current values are employed shows visibly different waveform in Fig. 5.

The machine performance of PMSG can be expressed by vector diagram and equivalent. Since the equivalent circuit parameters are known as presented in Table I, the curves of

TABLE II. CONDITIONS FOR FLUX DENSITY BY ARMATURE CURRENT

\begin{tabular}{c|c|c|c}
\hline \hline & Phase A (A) & Phase B (A) & Phase C (A) \\
\hline \hline Condition A & 1 & 0 & 0 \\
\hline Condition B & 0 & -0.5 & 0 \\
\hline Condition C & 0 & 0 & -0.5 \\
\hline Condition D & 1 & -0.5 & -0.5 \\
\hline \hline
\end{tabular}
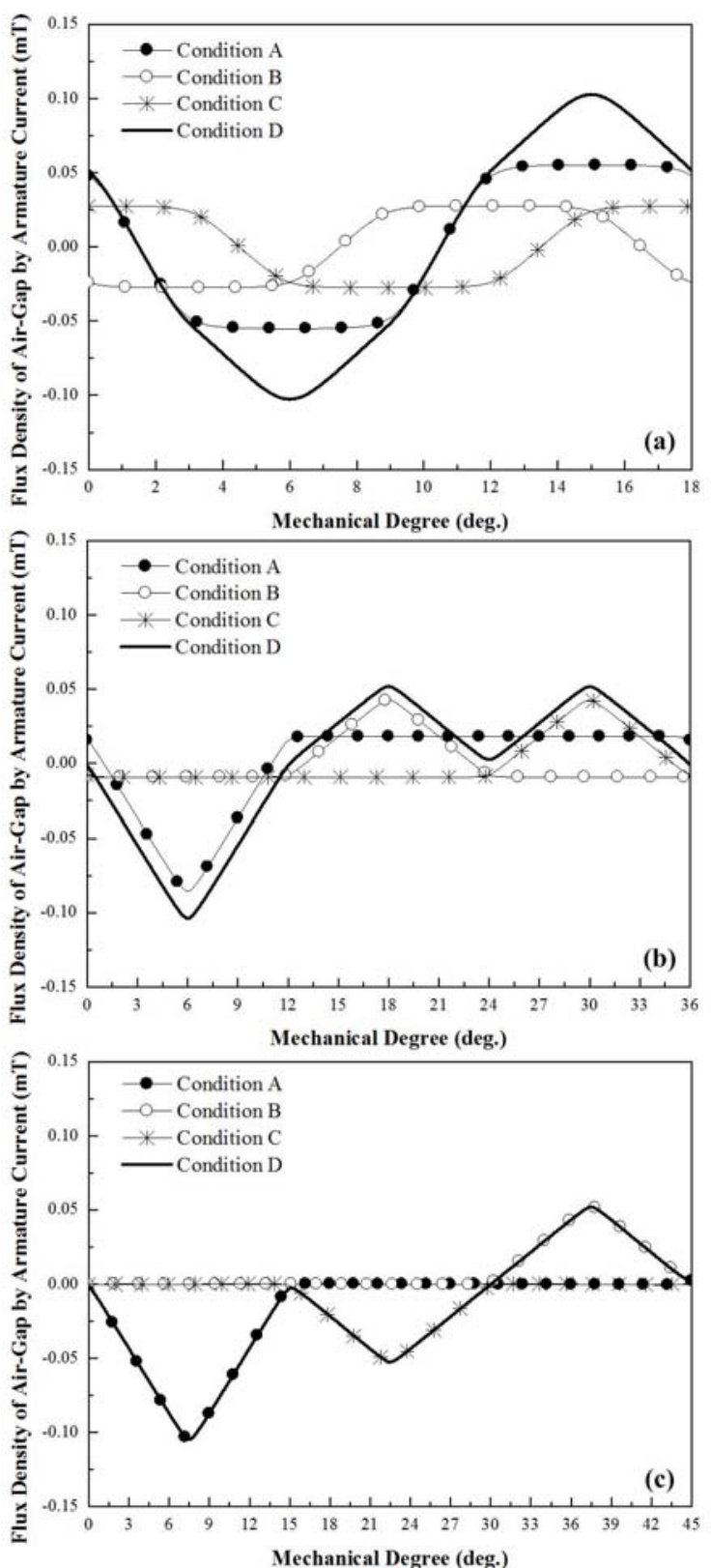

Figure 5. Radial component of flux density of air-gap by armature current without permanent magnets: (a) $\mathrm{CP}=9.0$, (b) $\mathrm{CP}=6.0$, (c) $\mathrm{CP}=7.5$

output power of the generators can be compared. In Fig. 6, the induced voltage of the presented analysis models is compared, and they have very similar waveform since they are designed for fair comparison. Besides, the waveform of the Model A can be compared by that of manufactured machine in Fig. 7, and the experimental induced voltage shows high correspondence in Fig. 8.

Based on the induced voltage, resistance and inductance, in Fig. 9, the load voltage, phase current and output power of the generators are compared according to their rotational speed conditions. Here, the maximum speed of the machines is $150(\mathrm{rpm})$. As can be confirmed in the figures, in the operating range, it is hard to find the visible difference while the values show the difference in high speed conditions. This is caused by the influence of the inductance, but it is no matter in that the generators are not operated in the high speed region. As a result, the comparison can be reasonable since the machines have identical voltage, current and power performance with different machine topology. In Fig. 10, the experimental voltage and current waveform of Model A are 

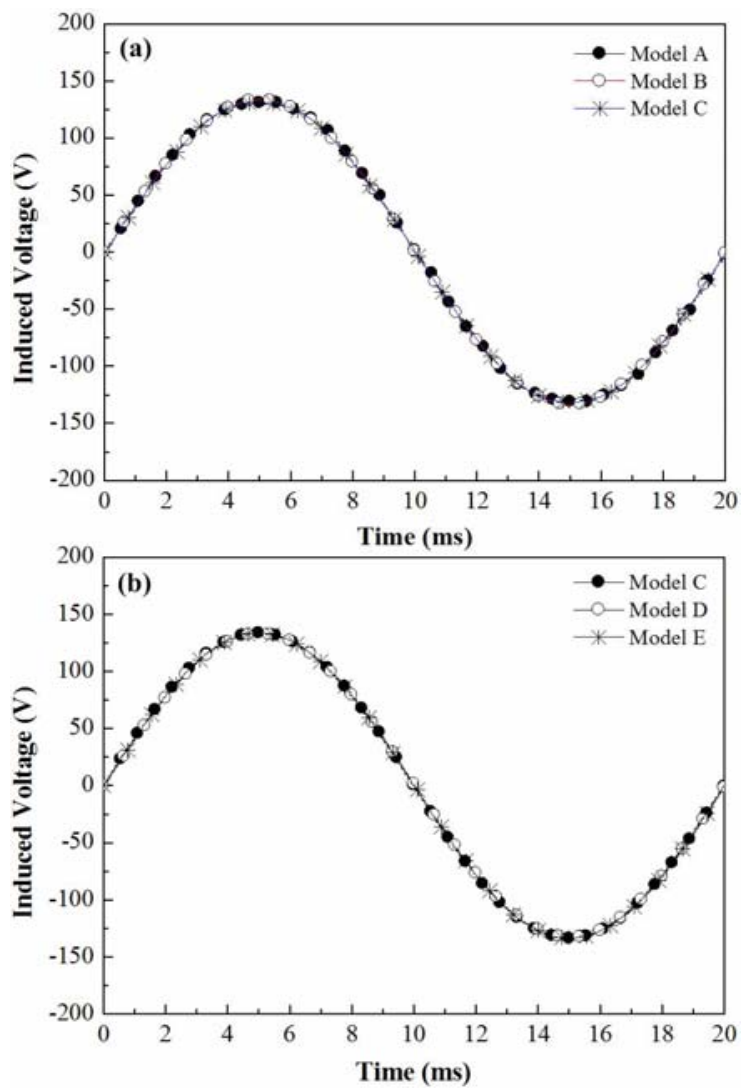

Figure 6. Induced voltage of analysis models in no-load condition at 150(rpm)

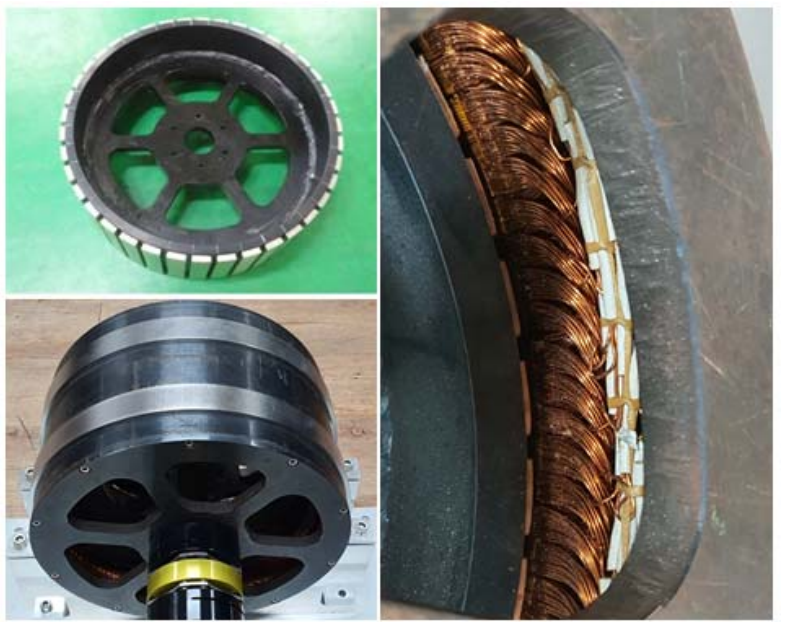

Figure 7 Manufactured PMSG for experimental verification (Model A) Parallel Magnetization with coil pitch 9.0 (deg.)

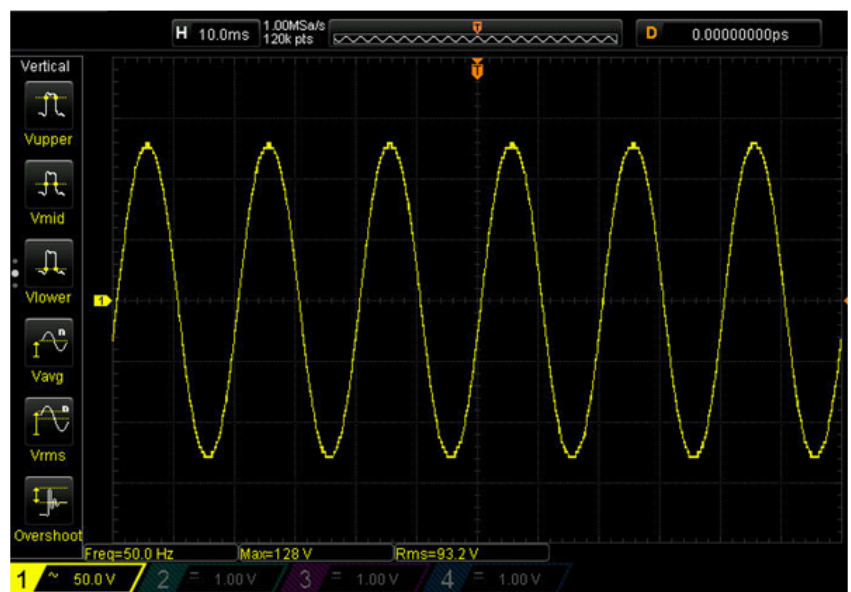

Figure 8. Experimentally measured induced voltage in no-load condition at 150(rpm)
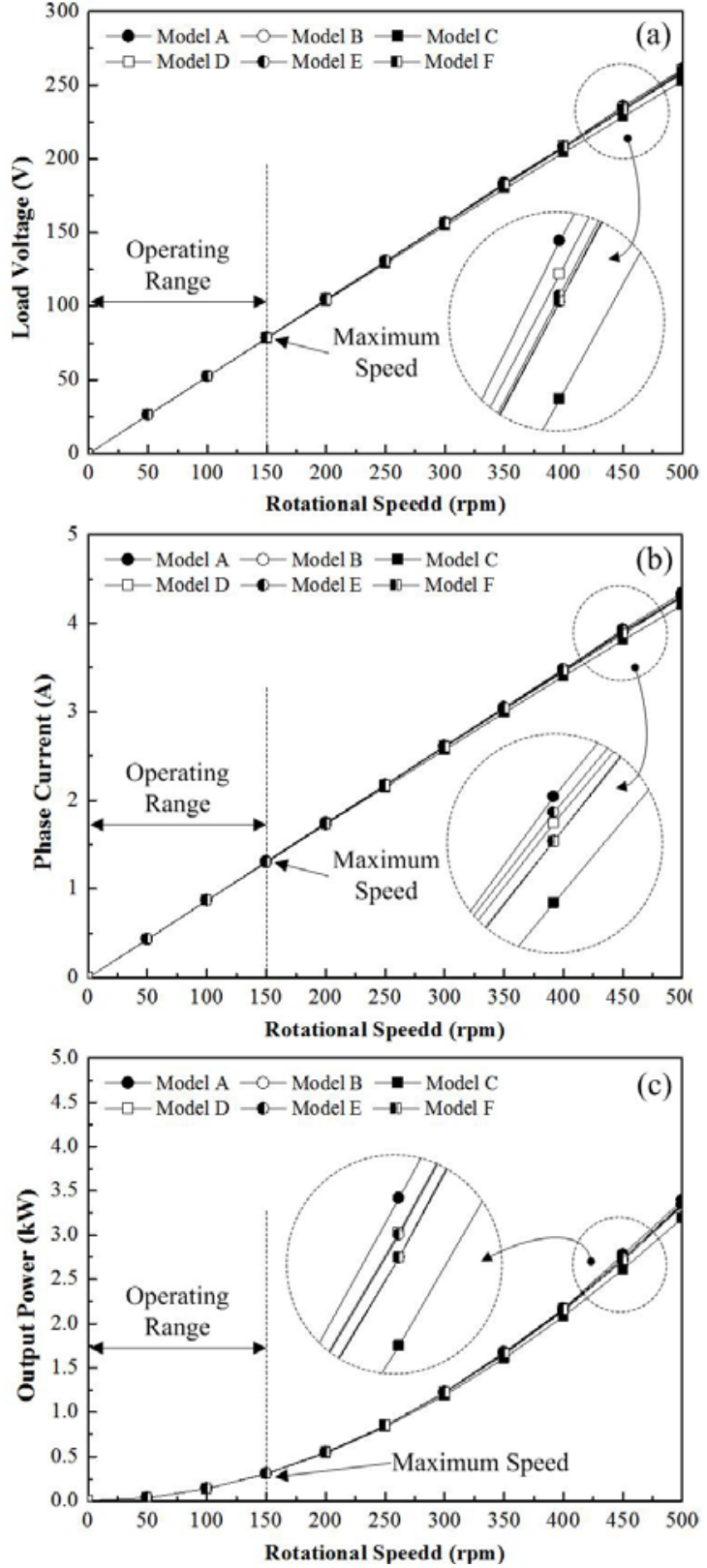

Figure 9. Generating characteristics according to rotational speed in AC load : (a) load voltage, (b) phase current, (c) output power

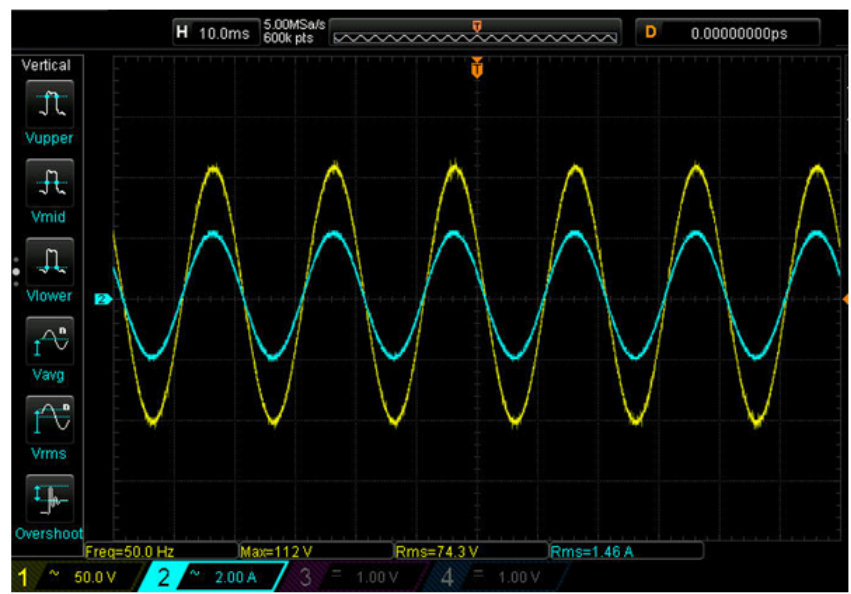

Figure 10. Experimentally measured voltage and current waveform in AC load condition at $150(\mathrm{rpm})$

presented, and their values can validate the analysis results. On the other hand, in this study, although the presented generators have the identical output power, their machine 

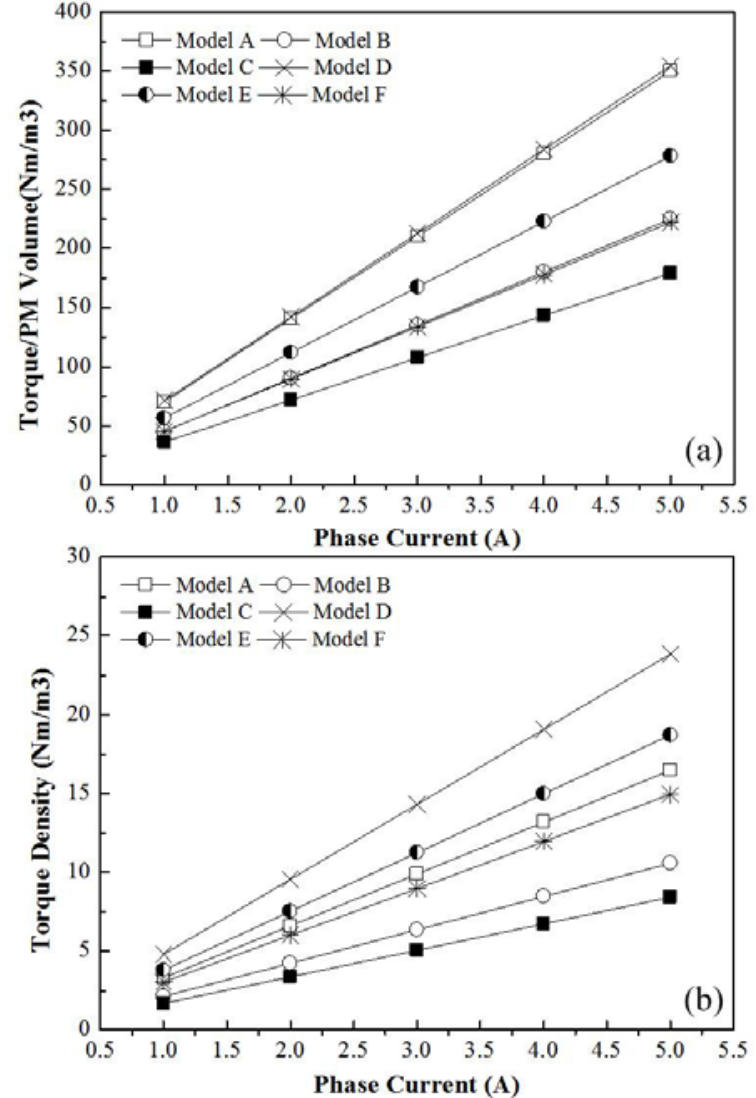

Figure 11. Torque characteristics according to phase current : (a) torque per magnet volume, (b) torque density

size is different according to the machine types. In other words, while the machine diameters are fixed, the axial length is different. Since the manufacturing cost and the machine size are important, the torque density is a good way to compare the machines.

In Fig. 11, the torque per PM volume and torque density of each machine according to phase current is compared. In low current condition, its difference is minor, but Model A and Model F show superior value of torque per PM volume

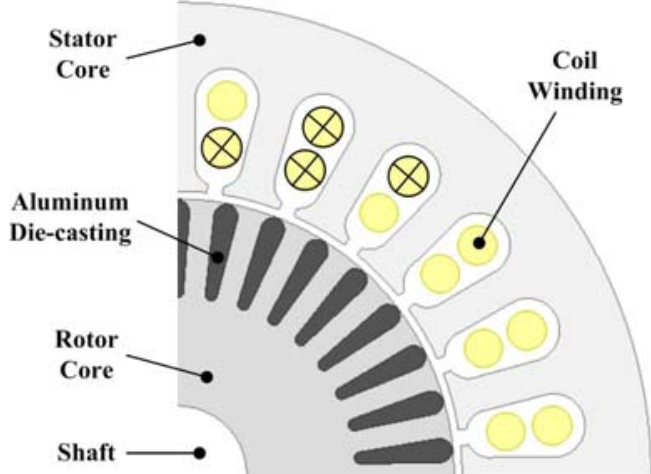

Figure 12. Electromagnetic structure of induction machine employed in MESS (1/4 model)

TABLE III. DESIGN SPECIFICATION OF INDUCTION MACHINE

\begin{tabular}{c|c|c}
\hline \hline Specification & unit & Value \\
\hline \hline Number of Poles & - & 4 \\
\hline Outer Dia. of Stator & $\mathrm{mm}$ & 118.6 \\
\hline Inner Dia. of Stator & $\mathrm{mm}$ & 71.2 \\
\hline Outer Dia. of Rotor & $\mathrm{mm}$ & 69.2 \\
\hline Inner Dia. of Rotor & $\mathrm{mm}$ & 17.2 \\
\hline Stack Length & $\mathrm{mm}$ & 55.4 \\
\hline Number of Parallel Branch & - & 2 \\
\hline Turns per phase & turns & 760 \\
\hline \hline
\end{tabular}

while the Model F presents highest torque density.

On the other hand, Fig. 12 shows the electromagnetic structure of the induction machine employed in the MESS. Since this study addresses the influence of the machine on generators while the mechanical energy is being stored, it is only operated in motoring mode in this study. As shown in the figure, the distribution coil winding is placed in stator core with 24 slot while the aluminum die-casting is applied in rotor core with 34 slots. Both stator and rotor cores are the silicon steel plate which is laminated to its axial direction for core loss reduction. More specific details are presented in Table III.

\section{INFLUENCE OF MECHANICAL ENERGY STORAGE ON PM WIND POWER GENERATORS WITH POWER CONVERTER}

Among the analysis models, the manufactured Model A presented before is employed for experiment, and Fig. 13 shows the constructed experimental set with power converters and MESS. As can be confirmed in the figure, the generator is connected to an operating motor with the operating inverter while the generator is integrated with power converters which are AC-DC-DC converter and SVPWM inverter having DC bus bar between them to operate MESS. The MESS is also integrated with a PM generator which plays a load machine.

Fig. 14 shows the measured systemic characteristic of the integrated PMSG and MESS for wind power application which is small-scale version for laboratory test. In the figure, the DC link voltage, the phase current of PMSG, the rotational speed of MESS and the phase current of MESS are simultaneously measured while the mechanical energy is

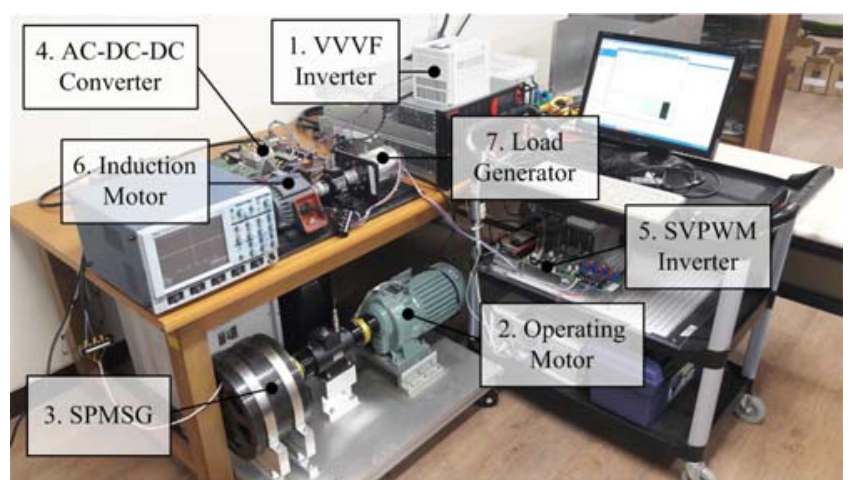

Figure 13. Experimental construction with manufactured PMSG (Model A), power converters and MESS

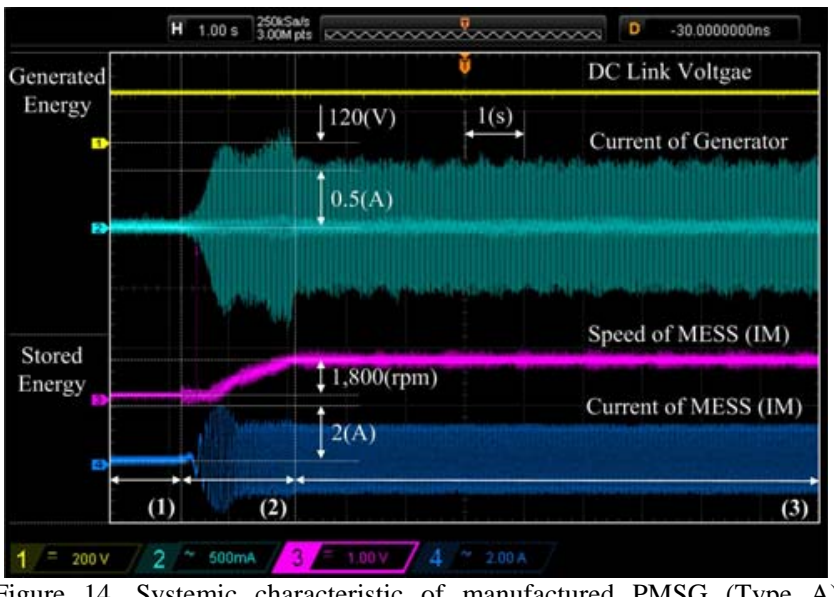

Figure 14. Systemic characteristic of manufactured PMSG (Type A) integrated with power converters and MESS when the generated energy is being stored 


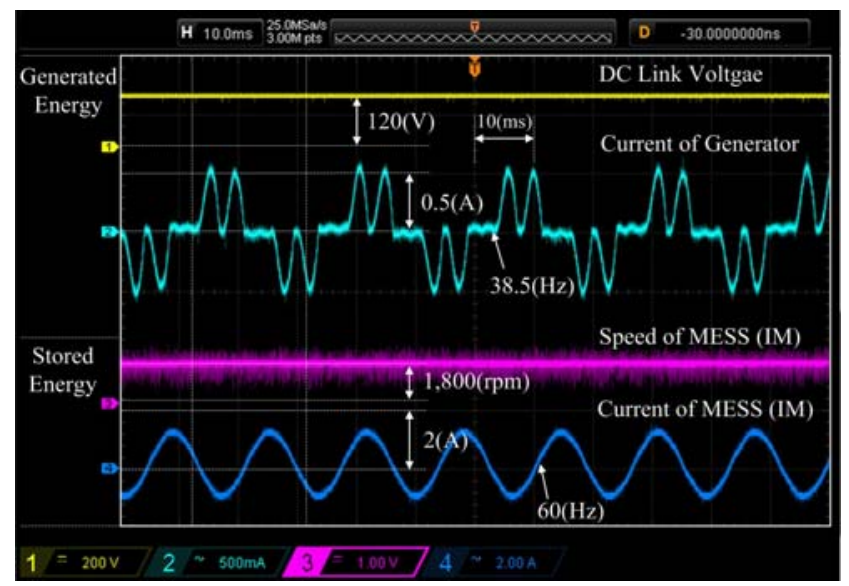

Figure 15. Each phase current of PMSG and IM when the rotational speed of MESS is $1,790(\mathrm{rpm})$

being stored. In addition, the generated energy and the stored energy parts are also indicated in the figure. In this experiment, since the rotational speed of the PMSG is controlled to be constant, the frequency of phase current is also constant while its value is varied according to the load conditions. On the other hand, the experiment can be largely divided into three regions. At first, as indicated in the figure, region (1) is no-load condition in which the IM of MESS is not operated. Therefore, the phase current of the PMSG is zero without any influence of the phase current on the machine. On the other hand, in the region (2), the MESS starts operating, so the phase current of the PMSG is varied according to the rotational speed of the MESS. Finally, in the region (3), the rotational speed of the IM is reached to the maximum value, and the phase current of the PMSG remains constant. The most important point of this experiment, the phase current of the PMSG is not sinusoidal due to the influence of the power converter as shown in Fig. 15. As presented in the previous study [20], the harmonics of the phase current in DC load condition has higher influence than AC load condition. Therefore, for more accurate investigation, the measured current is employed to the performance evaluation by electromagnetic field analysis in this study. Prior to the investigation of PMSGs for wind power generation system, it is highly necessary to analyze the induction motor while the mechanical energy is being stored. In Fig. 16, its entire characteristics of IM for MESS are presented.

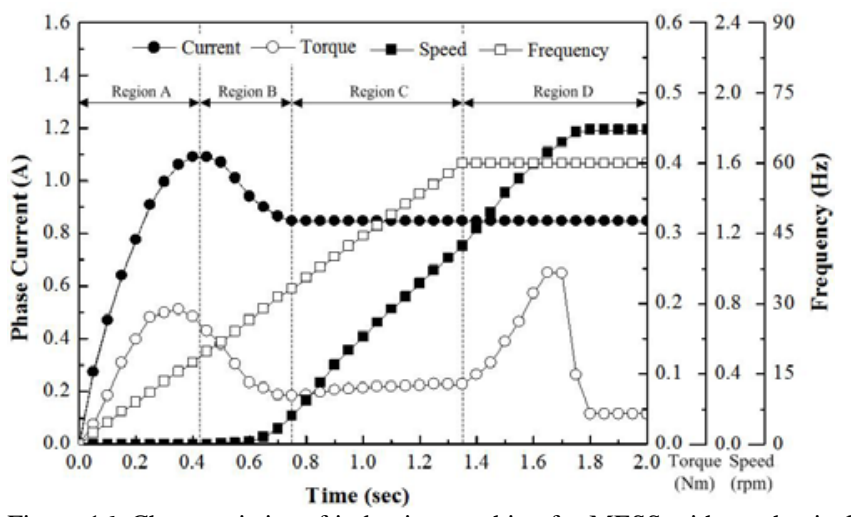

Figure 16. Characteristics of induction machine for MESS with mechanical energy storage

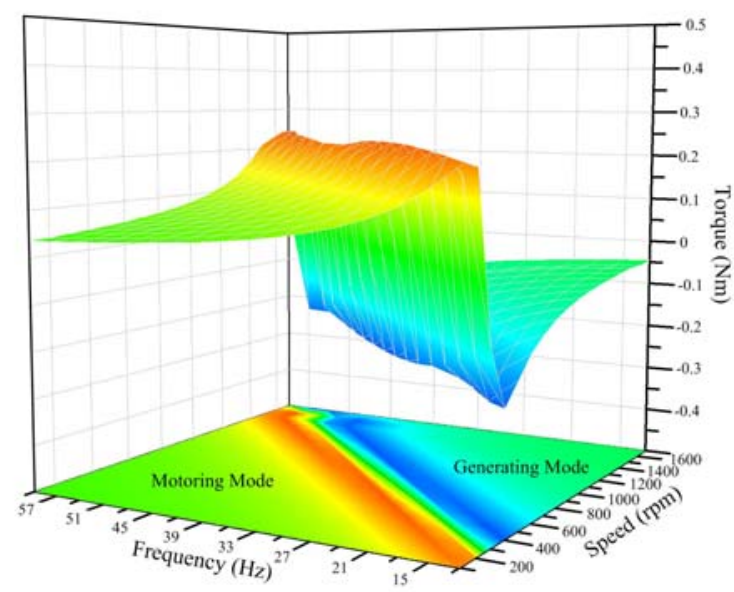

Figure 17. Torque characteristics according to variation of rotational speed and frequency in constant current condition (1.19Arms)

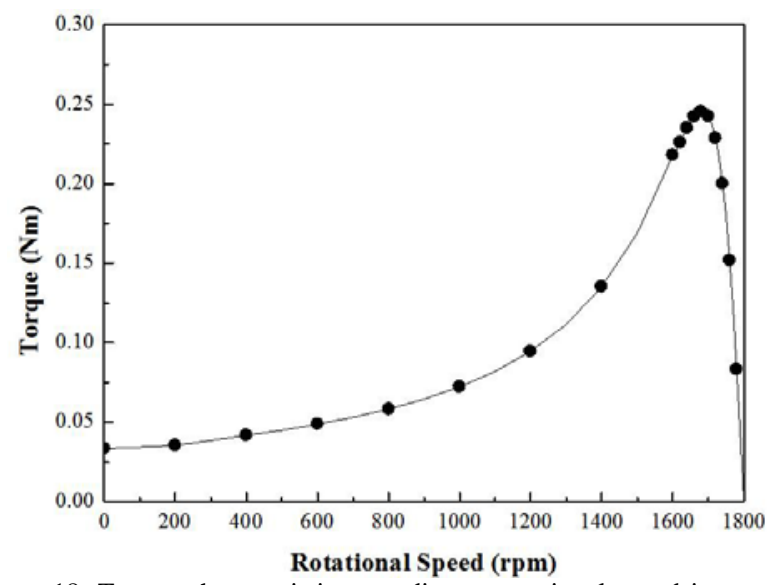

Figure 18. Torque characteristic according to rotational speed in constant current and frequency condition (1.19Arms, 60Hz)

The figure can be largely divided into four regions. At first, in Region A, the phase current which is maximum value is increased with increasing torque, and the MESS is not rotated yet. Therefore, the torque in the region is for initial operation of MESS. In Region B, since the MESS starts rotating, the current and torque values are decreased until they become constant in Region C. In Region A and Region $\mathrm{B}$, the input voltage of IM, namely output voltage of the integrated system of generator and power converter is constant, but the frequency is too low to start operating MESS. In the next step of Region C, the speed of MESS is increased while the frequency of current is also increased. In the region the torque shows very little difference. However, when the frequency is being constant in Region $\mathrm{D}$, the torque is largely increased until the rotational speed of MESS becomes constant. This can be explained by the electromagnetic field characteristic analysis results. At first, Fig. 17 presents the torque characteristics of the IM according to the variation of the frequency and the rotational speed under constant current condition. As can be confirmed in the figure, IM is operated by both motoring mode and generating mode with the operating conditions. Besides, it can be also found that the high torque is achieved when the speed is low with low frequency or when the speed is high with high frequency condition. On the other hand, Fig. 18 shows another torque characteristic with high frequency condition. In the figure, the increasing torque is presented while the speed is increased in high speed region. Therefore, 
the torque characteristics in each region can be explained.

\section{Performance Evaluation of PMSGs Based on CURRENT WITH HARMONICS}

The power losses of the generators can be various, such as electrical losses (copper loss, core loss and rotor loss) and mechanical losses (friction loss and windage loss). Since the mechanical loss can be neglected in low speed machines, this paper more focuses on the electrical losses. In this study, based on the measured current which has harmonic component due to the influence of the power converters, each power loss is analyzed based on FEM.
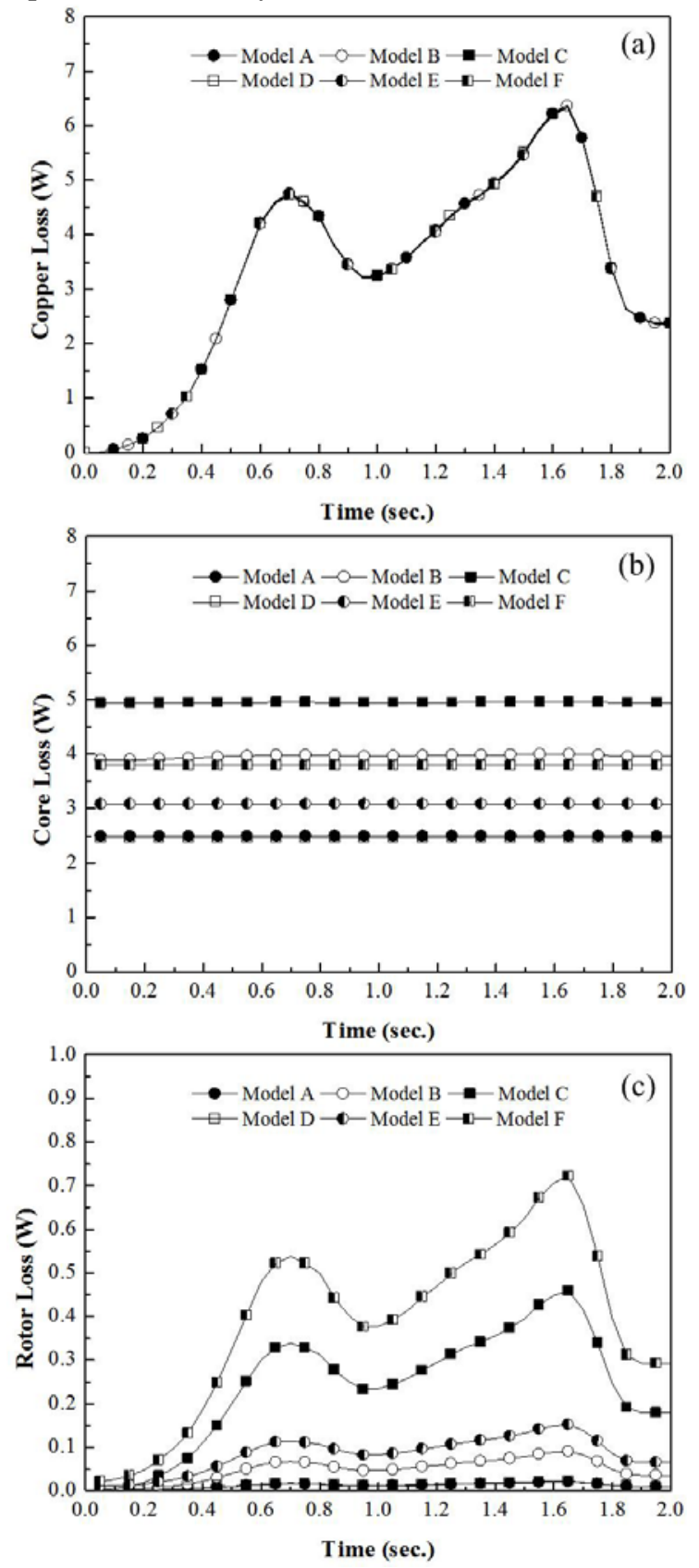

Figure 19. Power loss characteristics with mechanical energy storage : (a) copper loss, (b) core loss, (c) rotor loss

First of all, the copper loss of the generators can be calculated by integrating current density with inversed conductivity and length of coil winding [21]. Due to the low operating speed, the influence of the skin effect is not considered.

On the other hand, for the stator and rotor cores,
35PN250 from POSCO in Korea was employed with their lamination to minimize core loss. As shown in [22], the magnetic properties of the non-oriented silicon steel sheet is deteriorated by cutting method with sharp blade due to residual stress while grinding method is more effective to maintain the magnetic flux density. Since the stator and rotor cores in this paper are made by latter method, it is anticipated that the deterioration can be neglected.

The core loss can be illustrated by (6) which consists of hysteresis loss, eddy current loss and anomalous loss. Here, $k_{h}, k_{e}$ and $k_{a}$ imply the coefficients of each loss while $B$ and $f$ are respectively the flux density and the frequency. Although this equation which is known as Steinmetz equation is not sufficient for high speed machines, it is appropriate for the analysis models dealt with in this paper in that the maximum operating frequency is $50(\mathrm{~Hz})$ which is calculated by the number of poles and the rotational speed [23]. For much higher speed of machines, the magnetic behavior and harmonics of flux density can have high influence on the machine performance. In addition, the eddy current loss can be also influenced by stator slots as emphasized in [24] which is not addressed for the slotless machines death with in this paper.

$$
P_{c}=\sum_{i=1}^{\infty}\left(k_{h} f_{i} B_{i}+k_{e} f_{i}^{2} B_{i}^{2}+k_{a} f_{i}^{1.5} B_{i}^{1.5}\right)
$$

The rotor loss can be explained by (7) which is the function of current density and conductivity [25]. Here, T, $l$ and $J$ are the period of one electrical cycle, stack length and current density. In this study, the rotor loss is limited to the PMs. In low speed machines, the core loss in rotor core can be neglected. However, since the performance of PMs in the rotor of generators is highly influenced by the temperature condition, the reduction of the rotor loss is very important.

$$
P_{e d d y}=\sum_{i=1}^{\infty}\left(\frac{2}{T l} \int_{T} \int_{0}^{l} \frac{J_{i}^{2}}{\sigma} d z d t\right)
$$

The analyzed power losses are shown in Fig. 19. Since the phase current and resistance are almost identical, the copper loss shows well corresponded values. On the other hand, Model C shows highest core loss while Model F presents highest rotor loss. As can be confirmed in the figures, the copper loss and rotor loss are highly dependent on the mechanical energy storage, but core loss shows almost constant values.

For more thorough investigation of those power losses, the results are required to be addressed in detail. In the figure, the variation of copper loss and rotor loss is corresponded to the generator current of region (2) in Fig.14 where the mechanical energy is being stored. In particular, from the results of rotor loss, we can also confirm that Halbach magnetization pattern shows higher rotor loss in comparison with parallel magnetization pattern. In addition, the value of machine with coil pitch 7.5 (Model $\mathrm{C}$ and Model F) presents that it is not appropriate choice for generator design if the rotor loss is critical, for instance much larger scale machines. However, since the core loss is much more dominant than the rotor loss, Halbach 
magnetization pattern (Model F) is better determination than parallel magnetization (Model C) when the coil pitch is required.

\section{CONCLUSION}

In this paper, based on electromagnetic field analysis with FEM, the comparative characteristic analysis is performed according to machine types, mainly magnetization patterns and stator coil configuration by considering the influence of MESS on generator performance. For the reasonable comparison, the analyzed machines have almost identical equivalent circuit parameters and identical machine diameter while magnetization patterns and stator coil windings are differently employed. Besides, while the mechanical energy is being stored in the motoring mode of MESS, the systemic characteristics were specifically presented with a manufactured machine and constructed experimental set. The generator performance was investigated according to the characteristics of MESS. In addition, based on the measured current with harmonics, the power losses were also compared to investigate the influence of AC-DC-DC converter and SVPWM inverter in generator performance.

In conclusion, among various analysis models, Model C which is the machine with parallel magnetization pattern and 7.5 of CP value shows highest core loss value, and Model F which is the machine with Halbach magnetization pattern and 7.5 of CP value shows highest rotor loss values. When it comes to manufactured Model A, it showed lowest core loss and rotor loss, so it can be best selection of the machine topology for slotless PM wind power generators with MESS. Although this study addressed small-scale machine for the laboratory test, the analysis and performance evaluation results can be applied to larger scale machine for related wind power applications.

\section{REFERENCES}

[1] H. Li, Z. Chen, "Overview of different wind generator systems and their comparisons,” IET Renewable Power Generation, vol. 2, no. 2, pp. 123-138, Aug. 2008. doi:10.1049/iet-rpg:20070044

[2] C. Ocak, D. Uygun, I. Tarimer, "FEM based multi-criterion design and implementation of a PM synchronous wind generator by fully coupled co-simulation," Advances in Electrical and Computer Engineering, vol. 18, no. 1, pp. 37-42, Feb. 2018 doi:10.4316/AECE.2018.01005

[3] W. Gul, Q. Gao, W. Lenwari, "Optimal design of a 5-MW doublestator single-rotor pmsg for offshore direct drive wind turbines,” IEEE Transactions on Industry Applications, vol. 56, issue. 1, pp. 216-225, Jan. 2020. doi:10.1109/TIA.2019.2949545

[4] M. F. Iacchetti, G. M. Foglia, A. D. Gerlando, A. J. Forsyth, "Analytical evaluation of surface-mounted PMSG performances connected to a diode rectifier," IEEE Transactions on Energy Conversion, vol. 30, issue. 4, pp. 1367-1375, Dec. 2015. doi:10.1109/TEC.2015.2447935

[5] M. F. M. Arani, Y. A.-R. I. Mohamed, "assessment and enhancement of a full-scale PMSG-based wind power generator performance under faults,” IEEE Transactions on Energy Conversion, vol. 31, issue. 2, pp 728-739, Jun. 2016. doi:10.1109/TEC.2016.2526618

[6] D. Kowal, P. Sergeant, L. Dupré, H. Karmaker, "comparison of frequency and time-domain iron and magnet loss modeling including PWM harmonics in a PMSG for a wind energy application”, IEEE Transactions on Energy Conversion, vol. 30, issue. 2, pp. 476-486, Jun. 2015. doi:10.1109/TEC.2014.2373312

[7] Z. Zhang, Y. Zhao, W. Qiao, L. Qu, “A space-vector-modulated sensorless direct-torque control for direct-drive PMSG wind turbines,” IEEE Transactions on Industry Applications, vol. 50, issue. 4, pp. 2331-2341, Jul. 2014. doi:10.1109/TIA.2013.2296618
[8] M. S. Alam, M. A. Y. Abido, "Fault ride through capability enhancement of a large-scale PMSG wind system with bridge type fault current limiters," Advances in Electrical and Computer Engineering, vol. 18, no. 1, pp. 43-50, Feb. 2018. doi:10.4316/AECE.2018.01006

[9] Y. Tan, H. Zhang, Y. Zhou, "Fault detection method for permanent magnet synchronous generator wind energy converters using correlation features among three-phase currents," Journal of Modern Power Systems and Clean Energy, vol. 8, issue. 1, pp. 168-178, Jan. 2020. doi:10.35833/MPCE.2018.000347

[10] Y. Oner, N. Bekiroglu, S. Ozcira, "Dynamic analysis of permanent magnet synchronous generator with power electronics," Advances in Electrical and Computer Engineering, vol. 10, no. 2, pp. 11-15, May 2010. doi:10.4316/AECE.2010.02002

[11] M. M. R. Singaravel, S. A. Daniel, "MPPT with single DC-DC converter and inverter for grid-connected hybrid wind-driven PMSGPV system,” IEEE Transactions on Industrial Electronics, vol. 62, issue. 8, pp. 4849-4857, Aug. 2015. doi:10.1109/TIE.2015.2399277

[12] M. Davari, Y. A.-R. I. Mohamed, "Robust DC-link voltage control of a full-scale PMSG wind turbine for effective integration in DC grids," IEEE Transactions on Power Electronics, vol. 32, issue. 5, pp. 40214035, May 2017. doi:10.1109/TPEL.2016.2586119

[13] X. Zhang, J. Yang, "A DC-link voltage fast control strategy for highspeed PMSM/G in flywheel energy storage system,” IEEE Transactions on Industry Applications, vol. 54, issue. 2, pp. 1671 1679, Mar. 2018. doi:10.1109/TIA.2017.2783330

[14] P. B. Nempu, J. N. Sabhahit, "Stochastic algorithms for controller optimization of grid tied hybrid AC/DC microgrid with multiple renewable sources," Advances in Electrical and Computer Engineering, vol. 19, no. 2, pp. 53-60, May 2019. doi:10.4316/AECE.2019.02007

[15] M. Markovic, Y. Perriard, "Optimization design of a segmented halbach permanent-magnet motor using and analytical model,” IEEE Transactions on Magnetics, vol. 45, no. 7, pp. 2955-2960, July 2009. doi:10.1109/TMAG.2009.2015571

[16] G. Cimuca, S. Breban, M. M. Radulescu, C. Saudemont, B. Robyns, "Design and control strategies of an induction-machine-based flywheel energy storage system associated to a variable-speed wind generator,” IEEE Transactions on Energy Conversion, vol. 25, no. 2, pp. 526-534, Jun. 2010. doi:10.1109/TEC.2010.2045925

[17] M. N. Recheis, B. Schweighofer, P. Fulmek, H. Wegleiter, "Selection of magnetic materials for bearingless high-speed mobile flywheel energy storage systems,” IEEE Transactions on Magnetics, vol. 50, no. 4, pp. 8000604, Apr. 2014. doi:10.1109/TMAG.2013.2291938

[18] J. G. Bu, M. Zhou, X. D. Lan, K. X. Lv, “Optimization for airgap flux density waveform of flywheel motor using NSGA-2 and kriging model based on MaxPro design,” IEEE Transactions on Magnetics, vol. 53, no. 8, pp. 8203607, May 2017. doi:10.1109/TMAG.2017.2702758

[19] C. T. Liu, C. L. Lin, C. C. Hwang, C. H. Tu, “Compact model of a slotless tubular linear generator for renewable energy performance assessments," IEEE Transactions on Magnetics, vol. 46, no. 6, pp. 1467-1470, June 2010. doi:10.1109/TMAG.2010.2042037

[20] Y. S. Park, M. M. Koo, S. M. Jang, H. I. Park, J. Y. Choi, "Characteristic analysis of grid-connected pm wind power generators based on transfer relations and performance evaluation,” IEEE Transactions on Energy Conversion, vol. 28, no. 4, pp. 969-978, Dec. 2013. doi:10.1109/TEC.2013.2274528

[21] A. G. Sarigiannidis, A. G. Kladas, "Switching frequency impact on permanent magnet motors drive system for electric actuation applications,” IEEE Transactions on Magnetics, vol. 51, no. 3, pp. 8202204, Mar. 2015. doi:10.1109/TMAG.2014.2358378

[22] H. Lee, J. T. Park, "Effect of cut-edge residual stress on magnetic properties in non-oriented electrical steel," IEEE Transactions on Magnetics, vol. 55, no. 2, pp. 2000804, Feb. 2019. doi:10.1109/TMAG.2018.2866680

[23] R. Du, P. Robertson, “Dynamic Jiles-Atherton model for determining the magnetic power loss at high frequency in permanent magnet machines," IEEE Transactions on Magnetics, vol. 51, no. 6, pp. 7301210, Jun. 2015. doi:10.1109/TMAG.2014.2382594

[24] H. W. Jun, J. Lee, H. W. Lee, W. H. Kim, "Study on the optimal rotor retaining sleeve structure for the reduction of Eddy current loss in high-speed SPMSM,” IEEE Transactions on Magnetics, vol. 51, no. 3, pp. 8103004, Mar. 2015. doi:10.1109/TMAG.2014.2361861

[25] O. Bottauscio, G. Serra, M. Zucca, M. Chiampi, "Role of magnetic materials in a novel electrical motogenerator for the more electric aircraft," IEEE Transactions on Magnetics, vol. 50, no. 4, pp. 8200704, Apr. 2014. doi:10.1109/TMAG.2013.2284937 